\title{
Multimodality Management for Barcelona Clinic Liver Cancer Stage C Hepatocellular Carcinoma
}

\author{
Chihwan Choi ${ }^{\mathrm{a}}$ Gi Hong Choi ${ }^{\mathrm{b}}$ Tae Hyun Kim ${ }^{\mathrm{c}}$ \\ Masatoshi Tanakad Mao-Bin Meng $^{\text {e Jinsil Seonga }}$ \\ aDepartment of Radiation Oncology, Yonsei Cancer Center, ${ }^{b}$ Department of Surgery, \\ Severance Hospital, Yonsei University College of Medicine, Seoul, and ${ }^{\mathrm{C} C e n t e r ~ f o r ~ L i v e r ~ C a n c e r, ~}$ \\ Research Institute and Hospital, National Cancer Center, Goyang, Republic of Korea; \\ dDivision of Gastroenterology, Department of Medicine, Yokokura Hospital, Fukuoka, Japan; \\ eDepartment of Radiation Oncology and CyberKnife Center, Key Laboratory of Cancer Prevention and \\ Therapy, Tianjin Medical University Cancer Institute and Hospital, National Clinical Research Center of \\ Cancer, Tianjin, China
}

\section{Key Words}

Advanced stage $\cdot$ Hepatocellular carcinoma $\cdot$ Multimodality management $\cdot$ Staging systems

\begin{abstract}
This review summarizes the contents of a workshop on multimodality management for Barcelona Clinic Liver Cancer (BCLC) stage C hepatocellular carcinoma (HCC) held on July 6, 2013, under the auspices of the 4th Asia-Pacific Primary Liver Cancer Expert Meeting Scientific Advisory Committee. BCLC stage C HCC represents a varied disease spectrum and, therefore, further stratification of $B C L C$ stage $C$ should be explored. Although sorafenib is currently the standard treatment for BCLC stage $\mathrm{C} \mathrm{HCC}$, the survival benefits are modest and new treatment strategies are still needed. Based on the opinions of Asian experts, there are numerous alternative options aside from sorafenib for the treatment of BCLC stage $\mathrm{CHCC}$, including surgical resection, hepatic arterial infusion chemotherapy, transarterial chemoembolization, and external radiotherapy. Moreover, there are several studies on the multimodality management of BCLC stage C HCC, mainly in the form of retrospective studies and a few phase I and II trials. Multimodality management with combinations of various locoregional therapies or locoregional therapies with systemic targeted therapy using sorafenib needs to be actively
\end{abstract}


investigated. The Asia-Pacific clinical practice guidelines on multimodality management for $B C L C$ stage $\mathrm{CHCC}$ need recommendations based on the level of evidence, the strength of the data, and the strength of recommendations of previously reported systems.

Copyright $(2014$ S. Karger AG, Basel

\section{Introduction}

A workshop on multimodality management for Barcelona Clinic Liver Cancer (BCLC) stage C hepatocellular carcinoma (HCC) was held on July 6, 2013, under the auspices of the 4th Asia-Pacific Primary Liver Cancer Expert Meeting (APPLE) Scientific Advisory Committee. Several experts and observers from different specialties of HCC management, including hepatology, surgical oncology, and radiation oncology, participated in the workshop. The workshop was convened to discuss successful management of BCLC stage C (advanced stage) HCC using a multimodality approach. This communication is based on the observations made during the workshop and on reports from four experts from three Asian countries (Korea, Japan, and China) and contains an in-depth discussion by three experts on the panel.

\section{Why Multimodality Management is Advocated for BCLC Stage C (Advanced Stage) HCC}

There are several staging systems aimed at estimating the life expectancy of HCC patients, but only the BCLC staging and treatment strategy links staging with treatment $[1,2]$. BCLC stage $\mathrm{C}$ is defined as cases with an HCC-related Eastern Cooperative Oncology Group performance status of 1 or 2, macrovascular invasion (either segmental or portal invasion), or extrahepatic spread (lymph node involvement or metastases). According to the BCLC guidelines, and based on evidence from randomized clinical trials, only sorafenib is currently recommended for the treatment of BCLC stage C HCC. The Sorafenib Hepatocellular Carcinoma Assessment Randomized Protocol (SHARP) [3] and Asia-Pacific trial [4] found that treatment of HCC patients with sorafenib results in improved overall survival. However, most patients treated with sorafenib achieve only stable disease as the best radiologic response, with a median gain in overall survival of less than 3 months $[3,4]$. Therefore, additional management strategies need to be identified and optimized to improve therapeutic benefits.

BCLC stage C represents a varied disease spectrum. A proportion of patients in BCLC stage $C$ do not fulfill all the criteria for sorafenib allocation, and in those cases, the current advice is to offer the second most suitable option within the same stage. Moreover, treatment for locoregional HCC differs from the treatment for systemic HCC with extrahepatic spread and, therefore, BCLC stage C could potentially be subdivided into a locally advanced stage without extrahepatic spread and an extrahepatic advanced stage, based on the opinions of Asian experts $[5,6]$. Further stratification of patients within BCLC stage C according to liver function, prognostic molecular biomarkers, or prognostic variables should also be explored $[2,7]$.

According to the treatment algorithm used in Asian countries, various treatment modalities can be tried for BCLC stage C [8-15]. Multimodality management with combinations of various locoregional therapies such as transcatheter arterial chemoembolization (TACE) [16], hepatic arterial infusion chemotherapy (HAIC) [17], and radiotherapy (RT) [18-24], 


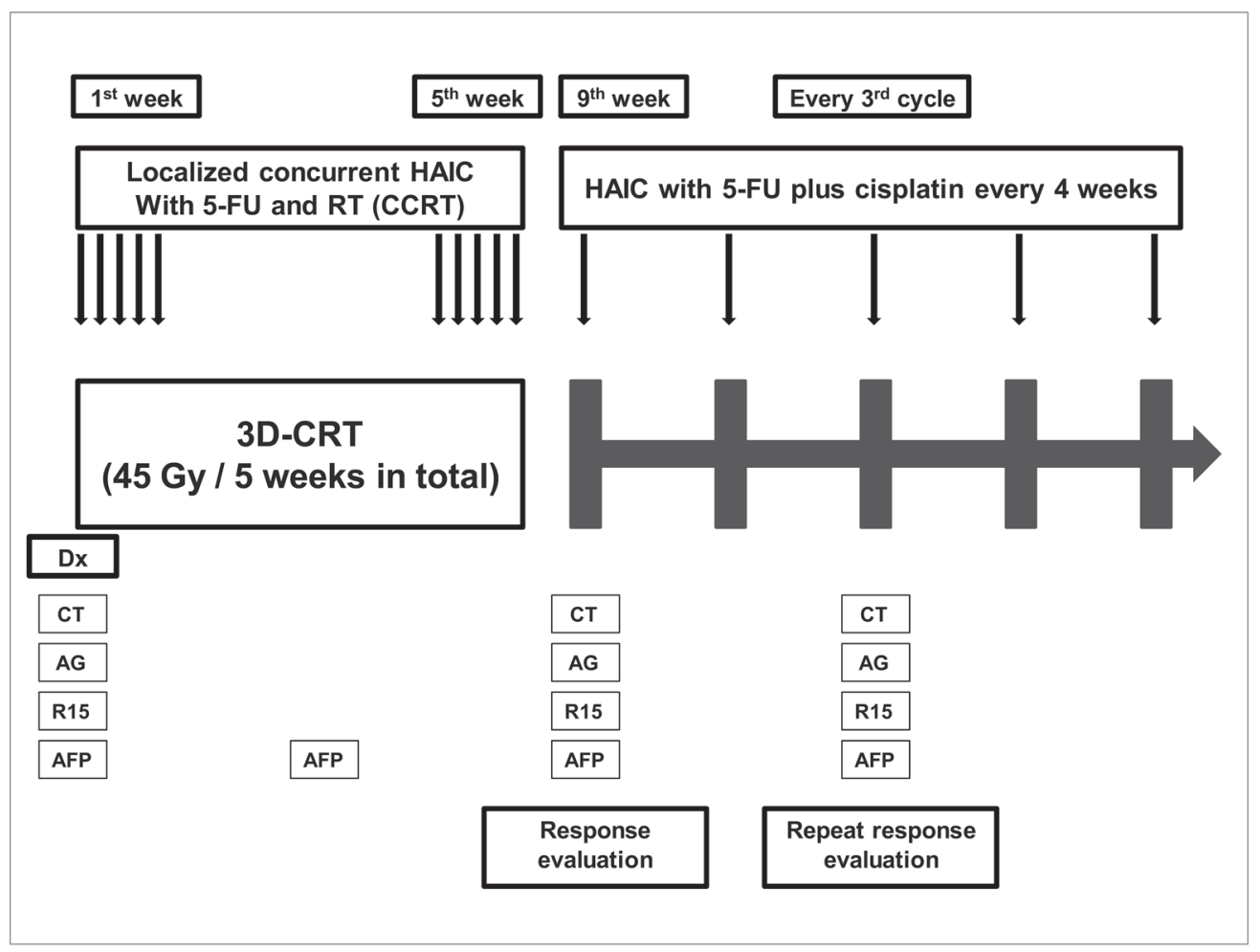

Fig. 1. Time course of localized concurrent intra-arterial chemotherapy plus external beam radiotherapy (CCRT) in patients with locally advanced hepatocellular carcinoma with portal vein tumor thrombus. $\mathrm{Dx}=$ diagnosis; $\mathrm{AG}=$ angiography; R15=indocyanine green R15; AFP=alpha-fetoprotein.

or combinations of locoregional therapies and targeted therapy using sorafenib may also be beneficial for BCLC stage C HCC [25-27].

\section{A Role for Intra-Arterial Chemotherapy as Part of the Multimodality Treatment for BCLC Stage C HCC}

Systemic therapies such as systemic chemotherapy, hormonal compounds, and immunotherapy, among others, have demonstrated inconclusive or negative results in previous studies and are generally regarded as inadequate because they are ineffective or result in high rates of toxicity [2]. Intra-arterial chemotherapy is associated with improved therapeutic effects because of the increased local concentration and lower systemic toxicity compared with systemic chemotherapy, and HAIC with anticancer agents such as high-dose 5-fluorouracil (5FU) or cisplatin has been demonstrated to achieve effective and safe results in patients with HCC with portal vein tumor thrombosis (PVTT) [17, 28-30].

Localized concurrent HAIC with 5-FU and RT followed by HAIC with 5-FU and cisplatin was tried in a pilot clinical trial for locally advanced HCC with PVTT [21]. All patients had Child Pugh A liver function. The drug was administered continuously for $24 \mathrm{~h}$ through the hepatic artery using an implanted infusion port concurrently with three-dimensional conformal RT (3D-CRT). The total RT dose was 45 Gy over 5 weeks, and the hepatic arterial infusion (HAI) consisted of $500 \mathrm{mg} /$ day of 5-FU administered during the first and fifth weeks of RT. After RT, HAI with 5-FU and cisplatin was administered every 4 weeks (fig. 1). The overall tumor 
response rate was $45 \%$ (18/40 patients), the 3 year overall survival rate was $24.1 \%$, and the median survival time was 13.1 months from the start of RT. Other studies, mostly retrospective, have established the efficacy of RT in treating HCC with PVTT, with reported median survival times ranging from 4 to 12 months and a generally favorable toxicity profile [31]. Furthermore, a combination of HAI 5-FU and subcutaneous interferon with image-guided RT (IGRT) for locally advanced HCC with PVTT has been compared with a non-IGRT patient group in a retrospective study; improved median survival (12.0 vs. 9.1 months) and time-toprogression (6.9 vs. 4.0 months) were apparent in the IGRT group [32].

HAIC provides moderate therapeutic efficacy and survival benefits with substantially tolerable toxicity profiles in patients with advanced HCC based on the opinions of Asian experts. A combination of HAIC and RT is a promising multimodality approach for the management of patients with locally advanced HCC with PVTT. However, a randomized clinical trial is required to assess the feasibility and efficacy of this approach.

\section{TACE Combined with RT for BCLC Stage C HCC}

TACE is the recommended treatment for BCLC stage B (intermediate stage) HCC and is considered as primary or palliative treatment for unresectable HCC [1, 2, 33]. However, its efficacy is unsatisfactory in most patients with PVTT, especially in patients with HCC with main portal vein invasion $[33,34]$. Some studies have shown that single TACE does not induced complete tumor necrosis, that repeated TACE frequently becomes ineffective because of tumor regression, and that TACE is contraindicated for patients with PVTT or inferior vena cava (IVC) invasion because of the potential risks of ischemic liver damage [22, 35]. Even in encapsulated tumors, which are the favorable tumor type indicated for TACE, the necrosis rate is reported to be only $44 \%$ when tumors are larger than $3 \mathrm{~cm}$ [36].

RT can effectively ameliorate the limitations of TACE through its antitumor and antivascular effects, and RT may also interact positively with the chemotherapeutic drug if the drug remains in the tumor after TACE [23]. In the first report of combination treatment using TACE and RT by Seong et al. [37], the overall tumor response rate was $63.3 \%$, with a median survival time of 17 months. Salvage RT has also been attempted for unresectable HCC patients when TACE has failed, resulting in a $66.7 \%$ response rate and a median survival time of 14 months [38]. In a previous non-randomized study comparing TACE followed by RT vs. TACE followed by no treatment or repeat TACE, a statistically significant improvement in survival was observed in patients treated with TACE plus RT compared to repeated TACE alone (2-year survival rate $37 \%$ vs. $14 \%$, respectively, $p<0.01$ ) [39]. A systematic review and meta-analysis involving a total of 1476 patients from 5 randomized controlled trials and 17 nonrandomized trials was performed in Asia [22]. The results of this meta-analysis showed that TACE plus RT, compared with TACE alone for unresectable HCC, significantly improved the survival and the tumor response of patients and was thus more therapeutically beneficial. Three approaches to the combination of TACE and RT have been reported $[22,40]$. The first approach involves using RT to treat PVTT only and using TACE to treat the primary HCC. The second approach involves delivering RT as a "consolidation" planned procedure to target cancer cells at the tumor periphery that may remain viable through blood supplied from collateral circulation or recanalization of the embolized artery after TACE [41]. The third approach involves RT being used as a salvage treatment option for unresponsive HCC despite repeated TACE. However, to select the optimum approach for combining TACE and RT, BCLC staging and identification of the extent of underlying liver functions should be considered, and randomized studies of TACE with or without RT are warranted. 
To the best of our knowledge, clear results regarding the significance of the optimal RT dose and appropriate fractionation for HCC patients treated with TACE plus RT have not yet been described. However, some retrospective studies demonstrated that the total RT dose was a significant prognostic factor for overall survival in HCC patients treated with TACE plus RT and should not be less than 45 Gy by conventional fractionation (i.e., 1.8-2 Gy/fraction, and five fractions per week) for targeting the primary tumor and PVTT [42, 43]. In a recent phase II nonrandomized trial of stereotactic body RT (SBRT) as a local salvage treatment after incomplete TACE in HCC patients, it was observed that an improved local control rate was significantly influenced by a higher RT dose (>54 Gy in three fractions) [44]. Taken together, these results suggest that escalation of the RT dose may improve local control and overall survival.

While TACE combined with RT is a promising treatment for unresectable HCC, further clarification regarding the optimal RT dose, optimal RT fractionation, and optimal interval between TACE and RT is still needed. A randomized study of TACE versus RT for BCLC stage C HCC without extrahepatic spread will help to clarify the role of RT in this setting.

\section{Downstaging after Concurrent Chemoradiotherapy - Opening the Door to Curative Treatment}

The majority of HCC patients are not diagnosed in the early stages of the disease and are therefore not eligible for potentially curative treatments such as surgical resection, liver transplantation (LT), or local ablation. Ideal candidates for curative treatment make up fewer than $30-40 \%$ of all diagnosed HCC cases $[1,2]$. The major limitation of LT as a curative treatment of HCC is the scarcity of donors. Increases in waiting time have led to approximately $20 \%$ of patients on waiting lists dropping out before undergoing LT [45]. Fortunately, downstaging using locoregional therapies, including TACE, radiofrequency ablation (RFA), HAIC, RT, and selective radioembolization with Yttrium-90-labeled microspheres, may offer patients who are not initially candidates for curative treatment a chance to undergo such treatment, e.g., resection or LT [20, 46-49]. Downstaging for resection or LT should be differentiated from neoadjuvant therapy: in the former, the tumor is unresectable before treatment either because of the local extent of the disease or because of distant metastasis, whereas in the latter, patients are within the Milan criteria, and treatments are given preoperatively to improve the results of surgery or to prevent tumor progression in patients on the waiting list for LT $[1,2,20]$.

In this workshop, institutional experiences of resection and LT after downstaging concurrent chemoradiotherapy (CCRT) were introduced by one Korean expert [unpublished data]. From 2005 to 2011, a total of 267 patients with locally advanced and unresectable HCC received CCRT followed by HAIC at one institution in Korea. CCRT followed by HAIC made it feasible to perform surgical resection in 41 (16.9\%) patients after downstaging and/or hypertrophy of the future remnant liver. Surgical resection after downstaging showed good longterm outcomes ( $49.6 \%$ overall 5 year survival rate) and offered the possibility of a cure in a proportion of patients with unresectable HCC. Living donor LT was performed as rescue treatment in nine patients with progressive deteriorating liver function after downstaging CCRT. The expert explained that the early results of LT after downstaging CCRT seem favorable, but that long-term oncologic outcomes must also be demonstrated before any conclusions can be drawn.

An example of a patient who underwent surgical resection after downstaging CCRT is illustrated in fig. 2. In brief, a 41-year-old man was diagnosed with hepatitis B virus (HBV)related HCC beyond the Milan criteria. A computed tomography (CT) scan demonstrated find- 

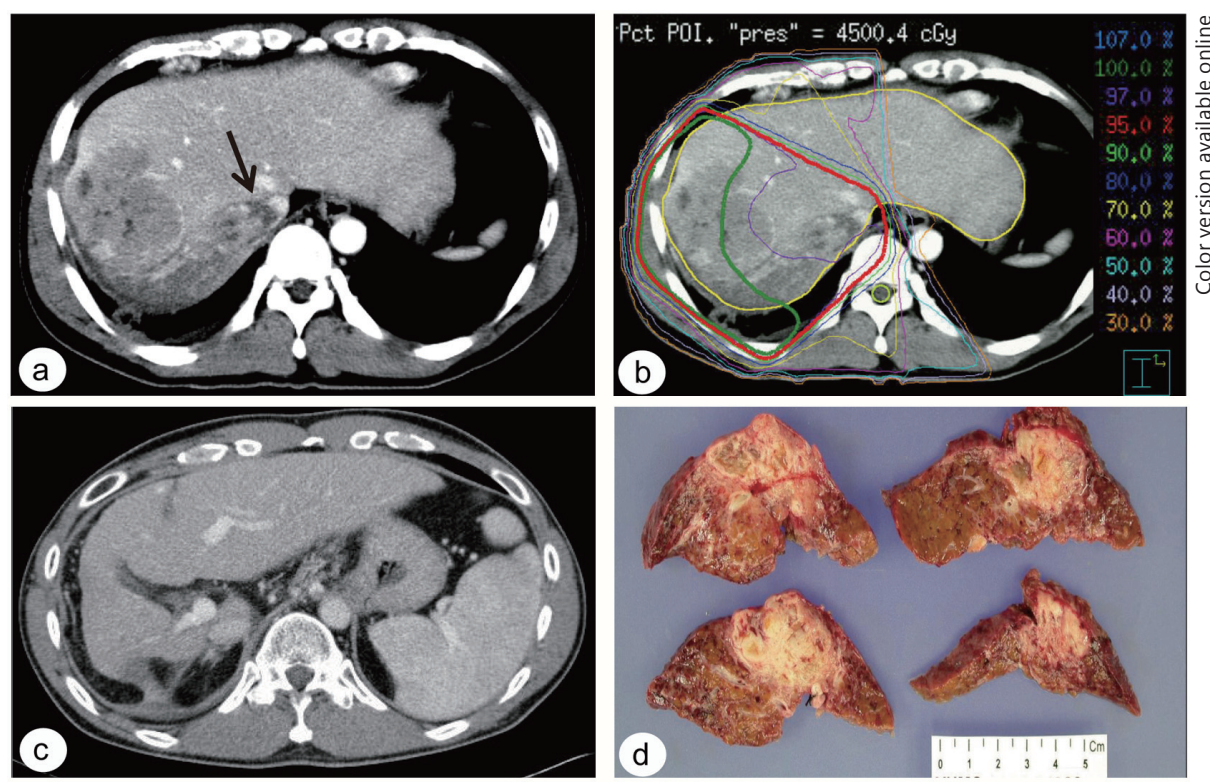

Fig. 2. (a) Initial dynamic CT scan of the liver in a 41 year-old patient with inferior vena cava thrombus (IVC, black arrow). (b) Isodose lines encompassing both the primary hepatocellular carcinoma and IVC thrombus, a bold yellow line encompassed normal organ ("Liver"). This line defined the outline of the liver. (c) Follow-up dynamic CT liver scan after concurrent chemoradiotherapy followed by the eleventh cycle of HAIC showing clinical complete response (disappearance of the IVC thrombus and arterial enhancing portion). (d) Surgical specimen from right hepatectomy showing pathologic complete tumor necrosis.

ings typical of liver cirrhosis and an approximately 11-cm hypervascular mass in the right lobe of the liver with invasion of the middle hepatic vein and IVC. The patient underwent CCRT (45 Gy in 25 fractions over 5 weeks with HAIC using 5-FU at a dose of $500 \mathrm{mg} /$ day administered during the first and fifth weeks of RT) as an initial treatment modality. This was followed by the combined use of HAIC using 5 -FU $\left(750 \mathrm{mg} / \mathrm{m}^{2}\right.$ for $5 \mathrm{~h}$ on days $\left.1-3\right)$ and cisplatin $\left(60 \mathrm{mg} / \mathrm{m}^{2}\right.$ for $2 \mathrm{~h}$ on day 2 ) every 4 weeks (from the third to the eleventh cycle of HAIC) to treat the remaining HCC. Because a clinical complete response (CR) was observed in the follow-up CT scan after these combination treatments, the patient underwent right hepatectomy with curative aim; complete pathologic tumor necrosis was noted. The patient was alive and recurrence-free 7 years post-treatment.

There are two unresolved issues for surgical resection after downstaging therapy: (1) the definition of unresectability of HCC and (2) the need for resection in tumors with clinical complete response (as determined by radiological findings or tumor markers) after downstaging therapy. The criteria for the unresectability of HCC depends on many factors, including the general condition of the patient, the stage of the disease, the liver function of the patient, and the choice of patient as well as the treatment protocol and availability of expertise in the individual medical center. Thus, the decision on whether HCC is resectable is still subjective. Although patients have reportedly experienced radiological CR after downstaging therapy, there is currently no evidence of a strong correlation between clinical and pathologic CR in the medical literature. Therefore, to induce a CR and to obtain pathological information, surgical resection may be required after tumor downstaging even in cases of radiological CR and tumor makers within the normal range.

Regarding downstaging therapy for resection or LT, to our knowledge, there have been no randomized trials, large case-control studies, or large well-designed cohort studies with 
patients treated consistently and properly followed-up [1, 2, 5, 6]. Furthermore, because studies on downstaging therapy followed by salvage resection are rare, the evidence in the medical literature regarding this approach is more limited than for downstaging therapy followed by LT [20]. Therefore, the role of surgical resection or LT after tumor downstaging in improving disease-free and overall survival in patients with unresectable HCC should be further investigated in well-designed prospective studies.

\section{Unresolved Issues Regarding the Use of RT as Part of Multimodality Treatment for BCLC Stage C HCC}

Although much progress has been made, many unresolved issues remain with respect to the use of RT as a part of multimodality treatment for BCLC stage C HCC. BCLC stage C HCC is often accompanied by macrovascular invasion, which decreases blood supply to the normal liver parenchyma and causes a deterioration in liver function, consequently limiting the application of TACE for HCC [50]. PVTT occasionally invades the IVC through the hepatic vein. Disseminated tumor thrombi can cause severe and lethal complications, such as pulmonary metastases, pulmonary infarction, or heart failure [51]. RT as a therapeutic option for relieving and/or stabilizing PVTT can delay intravascular tumor growth and the deterioration of liver function by preserving adequate portal flow; RT can also facilitate subsequent treatment of the primary HCC [50-52]. Overall tumor response rates of RT for HCC patients with PVTT have been reported to be $28.1-59.3 \%$, and the response to RT was correlated with better survival in several studies (table 1) [51-57].

There is currently no consensus regarding the optimal RT volume useful for HCC patients with PVTT [23]. Some studies included only PVTT in the RT volume, with the primary HCC being treated by local therapies such as TACE, resection, or RFA. However, if the primary tumor in these studies was small and was close to the PVTT in the RT volume, both the primary tumor and PVTT were irradiated [51-53], resulting in an overall tumor response rate of 45.5-50\%. Other studies included PVTT as well as primary HCC in the RT volume [54-56] and reported overall tumor response rates of 28.1-59.3\%, with CR rates lower than $10 \%$ (table 1). Although targeting both the primary tumor and PVTT appears to be associated with better overall outcomes than targeting PVTT alone, targeting PVTT alone may still be useful in some situations [23].

No consensus currently exists regarding the optimum RT dose and fractionation schedule for HCC. Direct comparison between studies is difficult because the survival of HCC patients depends largely on the degree of impairment of hepatic function, coexisting liver cirrhosis, and the extent of the tumor (e.g., number, size, tumor thrombosis extent). In a retrospective cohort study, various dose fractionation schemes such as multiple daily fractionation (hyperfractionation), conventional fractionation, and hypofractionation using SBRT were analyzed [58]. This study revealed that even with different dose schedules, a higher RT dose was associated with improved prognosis. Schemes of hypofractionation using SBRT and particle beam RT for HCC with PVTT have demonstrated promising outcomes in several studies [23, 31]; however, there are currently limited data available regarding the efficacy of this treatment for BCLC stage C HCC.

Non-irradiated liver is highly capable of regeneration and functional compensation, and the radiation tolerance dose of the liver depends on the irradiated liver volume [59]. A high RT dose can be delivered to a small volume of liver without significantly impairing its function. In RT planning, the irradiated volume of liver receiving a low RT dose ( $\leq 10 \mathrm{~Gy}$ ) is less of a concern than the irradiated volume of liver receiving a high RT dose. However, especially 
Table 1. Selected studies reporting results of radiotherapy for locally advanced hepatocellular carcinoma with portal vein tumor thrombus

\begin{tabular}{|c|c|c|c|c|c|c|}
\hline $\begin{array}{l}\text { Author, } \\
\text { year }\end{array}$ & $\begin{array}{l}\text { Patients } \\
\text { (no) }\end{array}$ & $\begin{array}{l}\text { Target } \\
\text { volume }\end{array}$ & $\begin{array}{l}\text { Treatment } \\
\text { modality }\end{array}$ & $\begin{array}{l}\text { Dose } \\
\text { (Gy) }\end{array}$ & $\begin{array}{l}\text { Response } \\
\text { rate }\end{array}$ & $\begin{array}{l}\text { Median survival } \\
\text { time (months) }\end{array}$ \\
\hline $\begin{array}{l}\text { Zeng et al., } \\
2005 \text { [51] }\end{array}$ & 44 & PVTT & $\begin{array}{l}\text { RT+TACE: } 25 \\
\text { RT+Resection: } 9 \\
\text { RT alone: } 10\end{array}$ & $36-60$ & $\begin{array}{l}\text { CR: } 34.1 \% \\
\text { PR: } 11.4 \%\end{array}$ & 8 \\
\hline $\begin{array}{l}\text { Nakagawa et al., } \\
2005 \text { [53] }\end{array}$ & 52 & PVTT & $\begin{array}{l}\text { RT+RFA/PEI: } \\
\text { 10 RT+TACE: } 25 \\
\text { RT+/RFA/PEI+TACE: } 8 \\
\text { RT alone: } 9\end{array}$ & $39-60$ & $\begin{array}{l}\text { CR: } 3.8 \%, \\
\text { PR: } 46.2 \%\end{array}$ & $\begin{array}{l}\text { 2-year: } 25.3 \% \\
3 \text {-year: } 15.2 \%\end{array}$ \\
\hline $\begin{array}{l}\text { Yoon et al., } \\
2012 \text { [52] }\end{array}$ & 412 & PVTT & RT+TACE & $21-60$ & $\begin{array}{l}\text { CR: } 3.7 \% \\
\text { PR: } 24.4 \%\end{array}$ & $\begin{array}{l}\text { Responders: } \\
19.4 \\
\text { Non-responders: } \\
7.0\end{array}$ \\
\hline $\begin{array}{l}\text { Kim et al., } \\
2005 \text { [54] }\end{array}$ & 59 & $\begin{array}{l}\text { Primary } \\
+ \text { PVTT }\end{array}$ & RT & $30-54$ & $\begin{array}{l}\text { CR: } 6.8 \% \\
\text { PR: } 39.0 \%\end{array}$ & $\begin{array}{l}\text { Responders: } \\
10.7 \\
\text { Non-responders: } \\
5.3\end{array}$ \\
\hline $\begin{array}{l}\text { Kim et al., } \\
2006 \text { [55] }\end{array}$ & 41 & $\begin{array}{l}\text { Primary } \\
+ \text { PVTT }\end{array}$ & RT & $44-54$ & $\begin{array}{l}\text { CR: } 9.7 \% \\
\text { PR: } 29.3 \%\end{array}$ & $\begin{array}{l}\text { Responders: } \\
20.1 \\
\text { Non-responders: } \\
7.2\end{array}$ \\
\hline $\begin{array}{l}\text { You et al., } \\
2007 \text { [56] }\end{array}$ & 27 & $\begin{array}{l}\text { Primary } \\
+ \text { PVTT }\end{array}$ & RT+TACE & $40-45$ & $\begin{array}{l}\text { CR: } 7.4 \%, \\
\text { PR: } 51.9 \%\end{array}$ & 13.5 \\
\hline
\end{tabular}

PEI=percutaneous ethanol injection; PR=partial response.

in HBV endemic areas, low RT doses are capable of inducing HBV reactivation or chronic hepatitis B exacerbation; we should thus minimize the use of low RT doses, monitor HBV DNA levels carefully after RT, and recommend antiretroviral therapy for hepatitis B patients before initiating RT for HCC $[60,61]$. Therefore, while low doses of RT are generally safe, the associated risks are not negligible.

Recent sequential phase I and II trials of SBRT for locally advanced HCC have demonstrated that SBRT can lead to sustained local control with a low risk of serious toxicity and is associated with survival rates higher than those for historical controls [62]. A total of $65.7 \%$ of the patients in this study were classified as BCLC stage C; the median overall survival was 17.0 months and the median time to progression was 6.0 months. However, tumor progression outside the SBRT field appeared to be a problem in this study. In another recent study aimed at investigating the effects of two administration schedules of sorafenib and RT in vitro and in vivo [25], it was demonstrated that sorafenib suppressed clonogenic survival after RT in HCC cells and enhanced the antitumor effect of RT in a dose-dependent manner. These results suggest that sorafenib plus RT could represent an effective management strategy for patients with BCLC stage C HCC; this strategy warrants further investigation. Furthermore, tumor progression outside the SBRT field may provide a rationale for combining SBRT with sorafenib [62]. A randomized phase III study of sorafenib versus SBRT followed by sorafenib in HCC (RTOG1112) is planned. Randomized clinical trials in the Asia-Pacific 
region for sorafenib versus RT combined with sorafenib, similar to the SHARP trial and AsiaPacific trial for sorafenib, are warranted.

\section{Conclusions}

The strength of evidence according to study design or end-points on multimodality management for BCLC stage C (advanced stage) HCC is weak. Although there are many retrospective studies on multimodality management for HCC of this stage, there are few studies in the form of phase I and II trials. As a result, a consensus for managing BCLC stage C HCC cannot be easily established. Thus, randomized controlled clinical trials or meta-analyses of randomized studies on multimodality management suitable for BCLC stage C HCC should be actively pursued. The consensus for successful management of BCLC stage C HCC using a multimodal approach should be further discussed at the upcoming APPLE meeting.

\section{Conflict of Interest}

The authors report no potential conflicts of interest.

\section{Acknowledgement}

This work was supported by a grant (0620390) from the National R\&D Program for Cancer Control, Ministry of Health and Welfare, Republic of Korea.

\section{References}

1 de Lope CR, Tremosini S, Forner A, Reig M, Bruix J: Management of HCC. J Hepatol 2012;56(Suppl 1):S75S87.

-2 European Association For The Study Of The Liver, European Organisation For Research, Treatment Of Cancer: Easl-eortc clinical practice guidelines: Management of hepatocellular carcinoma. J Hepatol 2012;56:908-943.

-3 Llovet JM, Ricci S, Mazzaferro V, Hilgard P, Gane E, Blanc JF, de Oliveira AC, Santoro A, Raoul JL, Forner A, Schwartz M, Porta C, Zeuzem S, Bolondi L, Greten TF, Galle PR, Seitz JF, Borbath I, Häussinger D, Giannaris T, Shan M, Moscovici M, Voliotis D, Bruix J, Group SI, SHARP Investigators Study Group: Sorafenib in advanced hepatocellular carcinoma. N Engl J Med 2008;359:378-390.

\4 Cheng AL, Kang YK, Chen Z, Tsao CJ, Qin S, Kim JS, Luo R, Feng J, Ye S, Yang TS, Xu J, Sun Y, Liang H, Liu J, Wang J, Tak WY, Pan H, Burock K, Zou J, Voliotis D, Guan Z: Efficacy and safety of sorafenib in patients in the Asia-Pacific region with advanced hepatocellular carcinoma: a phase III randomised, double-blind, placebo-controlled trial. Lancet Oncol 2009;10:25-34.

5 Han KH, Kudo M, Ye SL, Choi JY, Poon RT, Seong J, Park JW, Ichida T, Chung JW, Chow P, Cheng AL: Asian consensus workshop report: expert consensus guideline for the management of intermediate and advanced hepatocellular carcinoma in Asia. Oncology 2011;81(Suppl 1):158-164.

-6 Park HC, Seong J, Tanaka M, Zeng ZC, Lim HY, Guan S, Bae SH, Tak WY: Multidisciplinary management of nonresectable hepatocellular carcinoma. Oncology 2011;81(Suppl 1):134-140.

-7 Huitzil-Melendez FD, Capanu M, O’Reilly EM, Duffy A, Gansukh B, Saltz LL, Abou-Alfa GK: Advanced hepatocellular carcinoma: which staging systems best predict prognosis? J Clin Oncol 2010;28:2889-2895.

-8 Kokudo N, Makuuchi M: Evidence-based clinical practice guidelines for hepatocellular carcinoma in Japan: the J-HCC guidelines. J Gastroenterol 2009;44(Suppl 19):119-121.

-9 Korean Liver Cancer Study Group and National Cancer Center, Korea: Practice guidelines for management of hepatocellular carcinoma 2009. Korean J Hepatol 2009;15:391-423.

10 Lee JM, Han KH: Positioning and indication of sorafenib in the treatment algorithm and real practice setting: Western and eastern approach-Asian perspective. Oncology 2010;78(Suppl 1):167-171. 
11 Kudo M, Ueshima K: Positioning of a molecular-targeted agent, sorafenib, in the treatment algorithm for hepatocellular carcinoma and implication of many complete remission cases in Japan. Oncology 2010;78(Suppl 1):154-166.

12 Omata M, Lesmana LA, Tateishi R, Chen PJ, Lin SM, Yoshida H, Kudo M, Lee JM, Choi BI, Poon RT, Shiina S, Cheng AL, Jia JD, Obi S, Han KH, Jafri W, Chow P, Lim SG, Chawla YK, Budihusodo U, Gani RA, Lesmana CR, Putranto TA, Liaw YF, Sarin SK: Asian Pacific Association for the Study of the Liver consensus recommendations on hepatocellular carcinoma. Hepatol Int 2010;4:439-474.

13 Poon D, Anderson BO, Chen LT, Tanaka K, Lau WY, Van Cutsem E, Singh H, Chow WC, Ooi LL, Chow P, Khin MW, Koo WH, Asian Oncology Summit: Management of hepatocellular carcinoma in Asia: consensus statement from the Asian Oncology Summit 2009. Lancet Oncol 2009;10:1111-1118.

$\checkmark 14$ Yeo W, Chen PJ, Furuse J, Han KH, Hsu C, Lim HY, Moon H, Qin S, Yeoh EM, Ye SL: Eastern Asian expert panel opinion: designing clinical trials of molecular targeted therapy for hepatocellular carcinoma. BMC Cancer 2010;10:620.

15 Kim KM, Kim JH, Park IS, Ko GY, Yoon HK, Sung KB, Lim YS, Lee HC, Chung YH, Lee YS, Suh DJ: Reappraisal of repeated transarterial chemoembolization in the treatment of hepatocellular carcinoma with portal vein invasion. J Gastroenterol Hepatol 2009;24:806-814.

16 Lencioni R: Chemoembolization in patients with hepatocellular carcinoma. Liver Cancer 2012;1:41-50.

17 Kudo M: Treatment of advanced hepatocellular carcinoma with emphasis on hepatic arterial infusion chemotherapy and molecular targeted therapy. Liver Cancer 2012;1:62-70.

$\checkmark 18$ Jihye C, Jinsil S: Application of radiotherapeutic strategies in the BCLC-defined stages of hepatocellular carcinoma. Liver Cancer 2012;1:216-225.

19 Hsu HC, Chen TY, Chiu KW, Huang EY, Leung SW, Huang YJ, Wang CY: Three-dimensional conformal radiotherapy for the treatment of arteriovenous shunting in patients with hepatocellular carcinoma. $\mathrm{Br} \mathrm{J}$ Radiol 2007;80:38-42.

20 Lau WY, Lai EC: Salvage surgery following downstaging of unresectable hepatocellular carcinoma - a strategy to increase resectability. Ann Surg Oncol 2007;14:3301-3309.

21 Han KH, Seong J, Kim JK, Ahn SH, Lee Y, Chon CY: Pilot clinical trial of localized concurrent chemoradiation therapy for locally advanced hepatocellular carcinoma with portal vein thrombosis. Cancer 2008;113:995-1003.

22 Meng MB, Cui YL, Lu Y, She B, Chen Y, Guan YS, Zhang RM: Transcatheter arterial chemoembolization in combination with radiotherapy for unresectable hepatocellular carcinoma: A systematic review and meta-analysis. Radiother Oncol 2009;92:184-194.

23 Seong J: Challenge and hope in radiotherapy of hepatocellular carcinoma. Yonsei Med J 2009;50:601-612.

24 Choi SB, Kim KS, Park YN, Choi JS, Lee WJ, Seong J, Han KH, Lee JT: The efficacy of hepatic resection after neoadjuvant transarterial chemoembolization (TACE) and radiation therapy in hepatocellular carcinoma greater than $5 \mathrm{~cm}$ in size. J Korean Med Sci 2009;24:242-247.

25 Yu W, Gu K, Yu Z, Yuan D, He M, Ma N, Lai S, Zhao J, Ren Z, Zhang X, Shao C, Jiang GL: Sorafenib potentiates irradiation effect in hepatocellular carcinoma in vitro and in vivo. Cancer Lett 2013;329:109-117.

26 Lee S, Kim BK, Kim SU, Park Y, Chang S, Park JY, Kim Y, Ahn SH, Chon CY, Han KH: Efficacy of sorafenib monotherapy versus sorafenib-based loco-regional treatments in advanced hepatocellular carcinoma. PLoS ONE 2013;8:e77240.

27 Liapi E, Geschwind JF: Combination of local transcatheter arterial chemoembolization and systemic antiangiogenic therapy for unresectable hepatocellular carcinoma. Liver Cancer 2012;1:201-215.

-28 Ando E, Tanaka M, Yamashita F, Kuromatsu R, Yutani S, Fukumori K, Sumie S, Yano Y, Okuda K, Sata M: Hepatic arterial infusion chemotherapy for advanced hepatocellular carcinoma with portal vein tumor thrombosis: analysis of 48 cases. Cancer 2002;95:588-595.

29 Park JY, Ahn SH, Yoon YJ, Kim JK, Lee HW, Lee Y, Chon CY, Moon YM, Han KH: Repetitive short-course hepatic arterial infusion chemotherapy with high-dose 5-fluorouracil and cisplatin in patients with advanced hepatocellular carcinoma. Cancer 2007;110:129-137.

-30 Ueda H, Fukuchi H, Tanaka C: Toxicity and efficacy of hepatic arterial infusion chemotherapy for advanced hepatocellular carcinoma (review). Oncology Letters 2012;3:259-263.

31 Klein J, Dawson LA: Hepatocellular carcinoma radiation therapy: review of evidence and future opportunities. Int J Radiat Oncol Biol Phys 2013;87:22-32.

32 Chuma M, Taguchi H, Yamamoto Y, Shimizu S, Nakanishi M, Ogawa K, Sho T, Horimoto H, Kobayashi T, Nakai M, Terashita K, Sakuhara Y, Abo D, Tsukuda Y, Tsunematsu S, Hige S, Kato M, Shirato H, Asaka M: Efficacy of therapy for advanced hepatocellular carcinoma: intra-arterial 5-fluorouracil and subcutaneous interferon with image-guided radiation. J Gastroenterol Hepatol 2011;26:1123-1132.

-33 Llovet JM, Bruix J: Systematic review of randomized trials for unresectable hepatocellular carcinoma: Chemoembolization improves survival. Hepatology 2003;37:429-442.

34 Kim JH, Yoon HK, Kim SY, Kim KM, Ko GY, Gwon DI, Sung KB: Transcatheter arterial chemoembolization vs. chemoinfusion for unresectable hepatocellular carcinoma in patients with major portal vein thrombosis. Aliment Pharmacol Ther 2009;29:1291-1298.

-35 Yu YQ, Xu DB, Zhou XD, Lu JZ, Tang ZY, Mack P: Experience with liver resection after hepatic arterial chemoembolization for hepatocellular carcinoma. Cancer 1993;71:62-65.

-36 Higuchi T, Kikuchi M, Okazaki M: Hepatocellular carcinoma after transcatheter hepatic arterial embolization. A histopathologic study of 84 resected cases. Cancer 1994;73:2259-2267. 
37 Seong J, Keum KC, Han KH, Lee DY, Lee JT, Chon CY, Moon YM, Suh CO, Kim GE: Combined transcatheter arterial chemoembolization and local radiotherapy of unresectable hepatocellular carcinoma. Int J Radiat Oncol Biol Phys 1999;43:393-397.

-38 Seong J, Park HC, Han KH, Lee DY, Lee JT, Chon CY, Moon YM, Suh CO: Local radiotherapy for unresectable hepatocellular carcinoma patients who failed with transcatheter arterial chemoembolization. Int J Radiat Oncol Biol Phys 2000;47:1331-1335.

-39 Shim SJ, Seong J, Han KH, Chon CY, Suh CO, Lee JT: Local radiotherapy as a complement to incomplete transcatheter arterial chemoembolization in locally advanced hepatocellular carcinoma. Liver Int 2005;25:1189-1196.

40 Oh D, Lim H, Park HC, Paik SW, Koh KC, Lee JH, Choi MS, Yoo BC, Lim HK, Lee WJ, Rhim H, Shin SW, Park KB: Early three-dimensional conformal radiotherapy for patients with unresectable hepatocellular carcinoma after incomplete transcatheter arterial chemoembolization: a prospective evaluation of efficacy and toxicity. Am J Clin Oncol 2010;33:370-375.

41 Hawkins MA, Dawson LA: Radiation therapy for hepatocellular carcinoma: from palliation to cure. Cancer 2006;106:1653-1663.

-42 Xu LT, Zhou ZH, Lin JH, Chen Z, Wang K, Wang P, Zhu XY, Shen YH, Meng ZQ, Liu LM: Clinical study of transarterial chemoembolization combined with 3-dimensional conformal radiotherapy for hepatocellular carcinoma. Eur J Surg Oncol 2011;37:245-251.

43 Yu JI, Park HC, Lim H, Kim CJ, Oh D, Yoo BC, Paik SW, Kho KC, Lee JH: Scheduled interval trans-catheter arterial chemoembolization followed by radiation therapy in patients with unresectable hepatocellular carcinoma. J Korean Med Sci 2012;27:736-743.

44 Kang JK, Kim MS, Cho CK, Yang KM, Yoo HJ, Kim JH, Bae SH, Jung H, Kim KB, Lee DH, Han CJ, Kim J, Park SC, Kim YH: Stereotactic body radiation therapy for inoperable hepatocellular carcinoma as a local salvage treatment after incomplete transarterial chemoembolization. Cancer 2012;118:5424-5431.

-45 Yao FY, Ferrell L, Bass NM, Watson JJ, Bacchetti P, Venook A, Ascher NL, Roberts JP: Liver transplantation for hepatocellular carcinoma: expansion of the tumor size limits does not adversely impact survival. Hepatology 2001;33:1394-1403.

-46 Lei J, Yan L: Comparison between living donor liver transplantation recipients who met the milan and ucsf criteria after successful downstaging therapies. J Gastrointest Surg 2012;16:2120-2125.

47 Yu CY, Ou HY, Huang TL, Chen TY, Tsang LL, Chen CL, Cheng YF: Hepatocellular carcinoma downstaging in liver transplantation. Transplant Proc 2012;44:412-414.

48 Yoo EJ, Shin HS, Kim SU, Joo DJ, Park JY, Choi GH, Kim do Y, Ahn SH, Seong J, Koh MJ, Han KH, Chon CY: Orthotopic liver transplantation after the combined use of locoregional therapy and sorafenib for advanced hepatocellular carcinoma. OncoTarget Ther 2013;6:755-759.

49 Tang ZY, Zhou XD, Ma ZC, Wu ZQ, Fan J, Qin LX, Yu Y: Downstaging followed by resection plays a role in improving prognosis of unresectable hepatocellular carcinoma. Hepatobiliary Pancreat Dis Int 2004;3:495498.

50 Tazawa J, Maeda M, Sakai Y, Yamane M, Ohbayashi H, Kakinuma S, Miyasaka Y, Nagayama K, Enomoto N, Sato C: Radiation therapy in combination with transcatheter arterial chemoembolization for hepatocellular carcinoma with extensive portal vein involvement. J Gastroenterol Hepatol 2001;16:660-665.

51 Zeng ZC, Fan J, Tang ZY, Zhou J, Qin LX, Wang JH, Sun HC, Wang BL, Zhang JY, Jiang GL, Wang YQ: A comparison of treatment combinations with and without radiotherapy for hepatocellular carcinoma with portal vein and/or inferior vena cava tumor thrombus. Int J Radiat Oncol Biol Phys 2005;61:432-443.

52 Yoon SM, Lim YS, Won HJ, Kim JH, Kim KM, Lee HC, Chung YH, Lee YS, Lee SG, Park JH, Suh DJ: Radiotherapy plus transarterial chemoembolization for hepatocellular carcinoma invading the portal vein: long-term patient outcomes. Int J Radiat Oncol Biol Phys 2012;82:2004-2011.

53 Nakagawa K, Yamashita H, Shiraishi K, Nakamura N, Tago M, Igaki H, Hosoi Y, Shiina S, Omata M, Makuuchi M, Ohtomo K: Radiation therapy for portal venous invasion by hepatocellular carcinoma. World J Gastroenterol 2005;11:7237-7241.

54 Kim DY, Park W, Lim DH, Lee JH, Yoo BC, Paik SW, Kho KC, Kim TH, Ahn YC, Huh SJ: Three-dimensional conformal radiotherapy for portal vein thrombosis of hepatocellular carcinoma. Cancer 2005;103:2419-2426.

55 Kim TH, Kim DY, Park JW, Kim YI, Kim SH, Park HS, Lee WJ, Park SJ, Hong EK, Kim CM: Three-dimensional conformal radiotherapy of unresectable hepatocellular carcinoma patients for whom transcatheter arterial chemoembolization was ineffective or unsuitable. Am J Clin Oncol 2006;29:568-575.

56 You CR, Jang JW, Kang SH, Bae SH, Choi JY, Yoon SK, Choi IB, Lee DH, Chun HJ, Choi BG: Efficacy of transarterial chemolipiodolization with or without 3-dimensional conformal radiotherapy for huge HCC with portal vein tumor thrombosis. Korean J Hepatol 2007;13:378-386.

57 Yamada K, Izaki K, Sugimoto K, Mayahara H, Morita Y, Yoden E, Matsumoto S, Soejima T, Sugimura K: Prospective trial of combined transcatheter arterial chemoembolization and three-dimensional conformal radiotherapy for portal vein tumor thrombus in patients with unresectable hepatocellular carcinoma. Int J Radiat Oncol Biol Phys 2003;57:113-119.

58 Seong J, Lee IJ, Shim SJ, Lim do H, Kim TH, Kim JH, Jang HS, Kim MS, Chie EK, Kim JH, Nam TK, Lee HS, Han CJ: A multicenter retrospective cohort study of practice patterns and clinical outcome on radiotherapy for hepatocellular carcinoma in Korea. Liver Int 2009;29:147-152.

59 Lawrence TS, Ten Haken RK, Kessler ML, Robertson JM, Lyman JT, Lavigne ML, Brown MB, DuRoss DJ, Andrews JC, Ensminger WD, Lichter AS: The use of 3-D dose volume analysis to predict radiation hepatitis. Int J Radiat Oncol Biol Phys 1992;23:781-788. 
60 Kim TH, Kim DY, Park JW, Kim SH, Choi JI, Kim HB, Lee WJ, Park SJ, Hong EK, Kim CM: Dose-volumetric parameters predicting radiation-induced hepatic toxicity in unresectable hepatocellular carcinoma patients treated with three-dimensional conformal radiotherapy. Int J Radiat Oncol Biol Phys 2007;67:225231.

61 Kim JH, Park JW, Kim TH, Koh DW, Lee WJ, Kim CM: Hepatitis B virus reactivation after three-dimensional conformal radiotherapy in patients with hepatitis B virus-related hepatocellular carcinoma. Int J Radiat Oncol Biol Phys 2007;69:813-819.

-62 Bujold A, Massey CA, Kim JJ, Brierley J, Cho C, Wong RK, Dinniwell RE, Kassam Z, Ringash J, Cummings B, Sykes J, Sherman M, Knox JJ, Dawson LA: Sequential phase I and II trials of stereotactic body radiotherapy for locally advanced hepatocellular carcinoma. J Clin Oncol 2013;31:1631-1639. 